\title{
CONCEPÇÕES DA PSICOSSOCIOLOGIA SOBRE A PERSONALIDADE
}

\author{
Claudio Herbert Nina-e-Silva, Universidade de Rio Verde, claudio_herbert@yahoo.com.br \\ Lenny Francis Campos de Alvarenga, Universidade de Rio Verde.
}

\section{Recebido em: 28/05/2013 - Aprovado em: 30/07/2013 - Disponibilizado em: 15/08/2013}

Resumo: O objetivo do presente estudo foi apresentar as concepções da psicossociologia sobre a personalidade. As obras dos autores mais antigos relacionados à psicossociologia (Sartre, Lourau e Lapassade) foram analisadas a fim de verificar se havia reflexões desses autores sobre o desenvolvimento e a formação da personalidade, seja ela "normal" ou "patológica". Constatou-se que todos os três autores desenvolveram várias reflexões importantes sobre a forma pela qual as relações sociais moldam a personalidade. Observou-se que esses autores analisaram a formação da personalidade neurótica, formulando uma teoria psicossociológica sobre esse tema. Desse modo, sugere-se um aprofundamento da investigação da questão da personalidade na obra de outros autores relacionados ao movimento psicossociológico para uma ampliação dos achados do presente estudo.

Palavras-chave: existencialismo, neurose, personalidade, psicossociologia, Teoria Crítica, psicanálise.

Abstract: The aim of this study was to present the concepts of the psychosociology on personality. The works of the early authors related to psychosociology (Sartre, Lourau and Lapassade) were analyzed to see if there were reflections of these authors on the development and formation of personality, either "normal" or "pathological". It was found that all three authors have developed several important reflections on the way in which social relations shape the personality. It was observed that these authors analyzed the formation of the neurotic personality, formulating a psychological theory on this topic. Thus, it is suggested that further investigation into the issue of personality in the work of other authors related to the motion for an extension of psychosocial findings of this study.

Keywords: existencialism, neurosis, personality, psychosociology, Critical Theory, psychoanalysis.

\section{Introdução}

A Psicologia é o ramo da Ciência se ocupa do estudo das interações entre os seres vivos e o mundo que os envolve. Esse mundo envolvente pode ter natureza física ou simbólica, pode ser interno ou externo ao organismo (TROTTER, 1953).

Contudo, no caso de uma criatura social como o ser humano, o ambiente com o qual o indivíduo freqüentemente interage é representado por outras pessoas. Por sua vez, essas outras pessoas se relacionam com o indivíduo por meio de sua presença real e, sobretudo, através do significado que o próprio indivíduo atribui a esse relacionamento. A Psicologia Social se interessa justamente por essa interação física e simbólica entre as pessoas (MYERS, 2000).
Desse modo, o indivíduo, mesmo isolado, sempre está em relação com o outro. A inserção do indivíduo na sociedade se dá através de processos de objetivação e de subjetivação, isto é, interiorização e externalização de conteúdos de caráter social (KRÜGER, 1986).

No processo de objetivação, o indivíduo transforma o ambiente, modificando-o. Por sua vez, no processo de subjetivação, há a reação do ambiente à ação inicial do individuo: o ambiente transforma o indivíduo que, por sua vez, transforma-se. Portanto, o ideal seria se falar em termos de objetivação do indivíduo na sociedade e de subjetivação dos valores da sociedade pelo indivíduo.

A sociedade não é um lugar físico, concreto, mas uma objetivação dos indivíduos. A sociedade se constitui, portanto, 
no processo de objetivação da realidade subjetiva do sujeito. A partir desse pressuposto, compartilhado tanto pelo pontode-vista do materialismo histórico-dialético (Lane, 2001) quanto pelo interacionismo simbólico de George Mead, a sociedade não está "fora" do indivíduo, sendo antes um conjunto de valores, normas e crenças internalizadas durante o processo de socialização. Assim, o indivíduo se torna "social" quando a sociedade é internalizada por ele. Boa parte desse processo se dá de forma involuntária, por meio do processo de aprendizagem social.

Logo, o indivíduo nunca estará realmente "só", nunca será encontrado como um ser em si, pois, simultaneamente, ele se objetiva (comportando-se nas relações sociais) e subjetiva as consequências das relações sociais.

A internalização da realidade social é mediada por grupos. Por conta disso, os grupos se constituem em uma privilegiada e fundamental mediação dos processos de construção do indivíduo (subjetivação) e da sociedade (objetivação).

Dessa forma, a sociedade não é meramente o ambiente externo ao indivíduo, sendo antes um conjunto de normas e de valores internalizados por ele ao longo do processo de socialização.

A psicossociologia é considerada uma parte da psicologia social sociológica, caracterizada por uma intensa inspiração psicanalítica, embora possa ter também inspiração existencialista (MACHADO, 2010). De modo geral, a psicossociologia se preocupa com o estudo de grupos, organizações e comunidades, sobretudo inseridas no contexto do cotidiano. O objetivo principal da psicossociologia seria a promoção da intervenção a partir da análise da relação entre instituições e a formação da subjetividade (ENRIQUEZ, 2001).

Do ponto de vista psicossociológico, haveria uma distinção entre dois tipos de psicologia social: psicológica e sociológica. Costuma-se agrupar sob o rótulo de Psicologia Social Psicológica as atividades de psicólogos sociais que investigam a interação entre o ambiente social e os processos psicológicos individuais, tais como cognição, emoção, motivação e personalidade (CASE, FISHBEIN \& RITCHEY, 2006). Para tanto, a Psicologia Social Psicológica se utiliza do método experimental como principal fonte de produção de conhecimento sobre seus tópicos de investigação.

Por sua vez, a Psicologia Social Sociológica abrangeria aqueles pesquisadores que enfatizam a importância dos processos sócio-culturais, historicamente estabelecidos, nas interações entre os indivíduos (LANE \& CODO, 2001). Os métodos qualitativos nãoexperimentais são os preferidos pelos psicólogos sociais de inspiração sociológica. Além disso, a Psicologia Social Sociológica reivindica uma posição de crítica ao cientificismo positivista e individualista da 
Psicologia que não contribui para a superação de problemas sociais concretos (LANE \& CODO, 2001).

A questão do significado atribuído às relações sociais é relevante para o psicólogo social porque nem toda interação de uma pessoa com as demais é feita fisicamente, face-a-face. Em inúmeras ocasiões de nossas vidas, nós nos comportamos socialmente mesmo quando estamos sozinhos. Parcela fundamental de nossas interações sociais se processa simbolicamente e na ausência física das demais pessoas existencialista (MACHADO, 2010).

Portanto, a interação social estudada pelo psicólogo social engloba o nosso comportamento em relação a pessoas concretas e aos significados que aprendemos a partir de nossas experiências sócio-culturais (LANE \& CODO, 2001).

Por conta disso, torna-se importante investigar quais seriam as concepções psicossociológicas sobre a personalidade.

\section{Materiais e Métodos}

Este estudo foi uma pesquisa bibliográfica que consistiu na análise das principais obras de três autores comumente vinculados à Psicossociologia: Sartre, Lourau e Lapassade (ENRIQUEZ, 2001). Os textos de cada um desses autores foram analisados buscando-se verificar se os seus respectivos autores se ocupavam com questões relacionadas à personalidade, seja do pontode-vista psicopatológico ou não.

\section{Resultados e Discussão}

\subsection{Concepções existencialistas de Sartre} sobre a personalidade.

A leitura dos textos de Satre nos possibilitou a construção da noção de que esse filósofo discute uma teoria sobre a personalidade relacionando-a à Psicologia Social em termos do Existencialismo. O eu seria uma construção resultante dos atos intencionais do indivíduo no mundo (Blackburn, 1997). O existencialismo define o ser humano pelas ações que ele pratica, visto que “(...)o destino do homem está nas suas próprias mãos, não há esperança senão na sua ação e que a única coisa que permite ao homem viver é o ato (Sartre, 1973, p.11).

Sartre (1973) considerou que a inserção do indivíduo na sociedade se dá por meio de processos de objetivação e de subjetivação, isto é, interiorização e externalização de conteúdos simbólicos de caráter social. Na visão desse autor, o jogo dialético entre as subjetivações de um indivíduo e as objetivações que ele faz representa a interação deste indivíduo com o ambiente que o cerca. No processo de objetivação, o indivíduo transforma o ambiente, modificando-o. Por sua vez, no processo de subjetivação, há a contrapartida ambiental: o ambiente transforma o indivíduo que, por seu lado, transforma-se. Portanto, poder-se-ia falar em termos de objetivação do 
indivíduo e de subjetivação dos valores, normas e padrões culturais da sociedade pelo indivíduo. Desse modo, o social constitui o indivíduo, posto que a sociedade não é um lugar físico, mero aglomerado de pessoas, mas sim uma objetivação de indivíduos que compartilham da mesma cultura. A sociedade, por sua vez, constrói-se no processo de objetivação da realidade subjetiva do indivíduo. Torna-se apropriado, então, considerar que sociedade e indivíduo são interdependentes, não podendo ser tratados como entes separados (TROTTER, 1959).

O Existencialismo de Sartre (1973) parte do pressuposto de que a existência precede a essência, querendo dizer com isso que as ações e as escolhas do indivíduo no mundo, isto é a existência, definem a sua personalidade, os seus valores, as suas crenças, ou seja, a essência. Nesse sentido, a essência do ser humano está em contínua construção a partir da existência do indivíduo no mundo (SARTRE, 1960/2002).

. Dessa maneira, desde o momento do nascimento até a morte, o ser humano se encontra irremediavelmente sozinho e terrivelmente angustiado por estar “condenado a ser livre" (Sartre, 1973). Uma vez que cada pessoa é plenamente responsável por tudo aquilo que fizer na vida, uma personalidade neurótica seria aquela que tentaria transferir essa responsabilidade pessoal aos outros.

O neurótico sempre buscará respaldar as suas ações nas opiniões dos outros ou na moral, buscando se esquivar da responsabilidade pessoal por suas escolhas e, com isso, amenizar a angústia inerente ao processo de escolha. Contudo, trata-se de uma tentativa destinada ao fracasso, uma vez que a própria decisão de amparar as ações na opinião de uma pessoa e não de outra reflete uma escolha, fato que gera angústia, levando o neurótico a um sofrimento profundo e constante.

Portanto, a concepção existencialista considera que o "homem é o que ele faz. (...) O homem nada mais é do que uma série de empreendimentos, que ele é a soma, a organização, o conjunto de relações que constituem estes empreendimentos" (Sartre, 1973, p.20).

A partir do ponto de vista segundo o qual o homem é inteiramente livre e, portanto, responsável pelas suas próprias ações, Sartre condena todas as explicações para o comportamento humano baseadas em causas biológicas, psicológicas ou sociais que desconsiderem a responsabilidade individual pela ação.

$\mathrm{Na}$ terceira parte do livro "Crítica da Razão Dialética", Sartre (1960/2002) supõe que a experiência da existência humana reside no fato de haver uma ruptura, durante o nascimento, com um estado prévio de completude, experimentado na relação simbiótica mãe-feto. A condição de nascer coloca para o indivíduo, desde o princípio, a idéia de rompimento com a completude, com a integralidade. Portanto, a condição de ser se 
inaugura com a consciencia de se descobrir incompleto sempre. E à medida que o tempo passa, amplia-se a consciência de que a experiência da completude jamais se dará novamente.

Em vista disso, a formação da personalidade saudável implica, necessariamente, a aceitação do sentir-se incompleto, separado. Para Sartre (1960/2002), a criatura humana é o único ser capaz de se projetar, de se lançar ao futuro, e de se imaginar lá. E o que o ser humano visualiza quando se projeta no futuro é a separação, a dissolução, a morte inexorável. A constatação desse fato leva à angústia, à chamada "angústia de separação". Portanto, a condição da existência do ser humano é a angústia de separação.

A possibilidade da separação se inaugura no momento exato do encontro, no instante em que há a possibilidade de estabelecimento de uma relação afetiva. Daí decorre a angústia de separação essencial e inerente à condição humana. Quem não se encontra, não receia a separação. Mas o desejo do encontro é onipresente, o que produz um conflito entre: 1) permitir o encontro e experimentar a angústia da separação; ou 2)não permitir o encontro e experimentar a frustração do desejo.

O principal mecanismo de defesa que se estabelece para amenizar a angústia de separação é o isolamento afetivo. Embora haja um quê de serialidade, de fragmentação, nesse mecanismo, observa-se que "ficar" com alguém é mais confortável psicologicamente para o neurótico do que estar com alguém. Isso ocorre porque estar com alguém implica necessariamente a possibilidade de separação e, consequentemente, a experiência da angústia.

Nesse sentido, pode-se considerar que a relação com o outro é sempre um espaço de possibilidade de perda do outro e de mim mesmo. Quando há uma separação, o outro que parte leva consigo possibilidades de objetivações e de subjetivações que são minhas. Se a pessoa não aceitar a sua propria responsabilidade de retomar a vida Por conta disso, o ciúme é uma tentativa neurótica de buscar evitar a separação inevitável, tentando controlar o outro e mantê-lo sempre na relação. O problema é que o ciúme acaba afastando ainda mais o outro, gerando a própria separação que havia buscado evitar.

Portanto, o indivíduo pode ser considerado "social" a partir do momento em que ele aprende padrões culturalmente estabelecidos de agir, sentir e pensar mediado pelos grupos. Boa parte desse processo de subjetivação se dá de modo involuntário e compulsório no contexto cultural no qual o indivíduo se desenvolve. Logo, o indivíduo, uma vez socializado, nunca mais estará sozinho, nunca será encontrado como um ser em si e apenas por si, visto que, a todo tempo, ele se objetiva e é subjetivado (SARTRE, 1984). 


\subsection{Concepções de Georges Lapassade} sobre a personalidade.

O estudioso da psicossociologia francesa Georges Lapassade (1977) tenta compreender os processos grupais através do estudo das mediações externas, sobretudo dos meios de produção social. Para ele, quanto mais a sociedade evolui, mais o processo de produção social se fragmenta. Nesse sentido, em virtude da fragmentação do objeto que o homem produz, também ocorre a fragmentação do ser humano. $\mathrm{O}$ indivíduo, cada vez mais nas sociedades industrializadas, passa a ser percebido e a se perceber como um simples fragmento.

A questão da serialidade nos processos grupais proposta por Lapassade (1977) tem a sua origem na reflexão acerca do processo de desenvolvimento histórico dos meios de produção na sociedade capitalista. De acordo com esse autor, quanto mais a sociedade evolui, mais o processo de produção social se fragmenta como resultado do maior nível de especialização do trabalho. Nesse sentido, a forma de produção de nossa sociedade industrial e tecnológica tem um caráter de segmentação e fragmentação que se reflete nas estruturas e dinâmicas grupais. Logo, o indivíduo passa a ser percebido e a perceber as suas relações interpessoais como meros fragmentos de um todo incompreensível.

De acordo com LAPASSADE (1977), essa percepção fragmentada da realidade por parte dos indivíduos impede que o grupo atinja adequadamente os seus objetivos de coesão e de totalização. A totalização se refere à necessidade de relação afetiva entre membros de um grupo que buscam, na relação uns com os outros, uma sensação de estarem completos e plenos.

Dessa maneira, Lapassade (1977) considera que a forma de produção em série de nossa sociedade industrial tem um caráter de segmentação que se reflete na personalidade do indivíduo e que, por sua vez, reproduz-se nas instituições e relações sociais. Logo, o indivíduo fragmentado da sociedade contemporânea se torna incapaz de compreender os processos de objetivação e de subjetivação, os quais se tornam mecânicos, padronizados e destituíduos de individualidade.

Lapassade (1977) afirma que o as pessoas em um grupo na contemporaneidade vivem em estado permanente de contradição entre um desejo de totalização e uma tendência à segmentalidade, a uma realidade altamente fragmentada e que leva a uma angústia de separação ainda mais intensa. Há, portanto, entre as pessoas da atualidade, uma vontade de união que se contrapõe a uma realidade marcada pela segmentalidade determinada pelo modo de produção serializado da indústria.

\subsection{Concepções da Análise Institucional de René Lourau sobre a personaliade.}

Tomando como base a categoria de análise de Lapassade, Lourau (1997) afirma 
que quanto maior a transversalidade, maior será a tendência do grupo à segmentalidade e maior será a fragmentação da personalidade. O ser humano no mundo industrial não tem mais a uma compreensão total de sua personalidade, sendo percebido e, dialeticamente, percebendo-se, como um fragmento isolado do restante da personalidade.

Lourau (1997) investiga a influência das instituições nas relações grupais e, por consequência, na formação da personalidade dos indivíduos que constituem os grupos. Para ele, uma instituição é um conjunto de regras seguido por determinado grupo. Nesse sentido, "uma norma universal, ou considerada como tal, quer se trate do casamento ou da educação (...) chama-se instituição. O fato de fundar uma família, o ato do casamento (...) são fenômenos que também recebem o nome de instituição" (Lourau, 1997, p.9).

As instituições atravessam as relações sociais, fazendo com que interajam papéis entre si e não pessoas entre si (Lourau, 1997). Na universidade, por exemplo, o que ocorrem são relações entre papéis definidos por instituições (alunos/professor) e não entre pessoas (fulano/beltrano).

O conceito de transversalidade é fundamental para a análise institucional. Segundo LOURAU (1997), a transversalidade diz respeito ao processo pelo qual as relações entre os componentes de um dado grupo são influenciadas por instituições externas ao grupo. Em outras palavras, a transversalidade pode ser definida como um processo de decisão que é definido e imposto de fora para dentro de um grupo. Considerando-se que a sociedade se organiza por meio de instituições, muitas decisões de grupo são mediadas por valores externos culturalmente estabelecidos. Em termos gerais, seria lícito afirmar que quanto maior a transversalidade, menor a consciência dos indivíduos na relação grupal em que estão envolvidos, bem como mais suscetível à influência externa será esse grupo.

Como exemplo dessa questão, podemos analisar o conteúdo da frase "eи não traio a minha esposa porque é pecado". Essa afirmação sugere um alto nível de transversalidade, posto que o empecilho para a ação adúltera do marido não seria o seu próprio desejo e convicção acerca da importância do voto de fidelidade, mas sim uma norma religiosa externa. Por outro lado, demonstraria baixo nível de transversalidade a afirmação "eu não traio a minha esposa porque eu não quero", visto que o obstáculo à traição seria uma consciência própria do indivíduo, ainda que, naturalmente, essa consciência possa ter sido construída a partir de valores morais e religiosos externos. O que está em causa nessa discussão é a origem do controle do comportamento do indivíduo.

$$
\text { A transversalidade, desse modo, }
$$
ocorre quando as instituições influenciam as relações entre indivíduos (Lourau, 1997). Nesse sentido, as relações entre as pessoas são atravessadas por transversalidades 
institucionais, as quais se constituem em interferências de normas e valores exteriores na forma como as pessoas se relacionam.

Desse modo, as transversalidades limitam as possibilidades de atuação das pessoas em uma relação, pois as transversalidades impõem padrões de conduta, de pensamento e de emoção. A transversalidade não leva em conta a vontade, a consciência e a responsabilidade individual. Por conta disso, quando ocorre a transversalidade, até mesmo as decisões tomadas pelas pessoas em uma relação são feitas fora dela, pois são mediadas por normas ou expectativas externas à relação.

De acordo com Lane e Codo (2001, p.35),

"É através da análise da transversalidade que se torna possível o conhecimento da segmentaridade do grupo e da sua autonomia, bem como de seus limites, condição para um grupo se tornar grupo-sujeito, isto é, aquele que percebe a mediação institucional, objetiva e conscientemente".

Um casamento altamente transversalizado, por exemplo, não é uma relação instituinte, mas sim instituída, visto que os cônjuges meramente exercem os papéis pré-determinados socialmente de "marido" e de "esposa", ao invés de duas pessoas plenas e conscientes. Em uma relação instituída assim, a conseqüência natural é o aparecimento do autoritarismo, representado pelo ciúme, para sustentar a coesão do casal.
De acordo com Lourau (1997), quanto maior a transversalidade em uma relação, menor a consciência dos indivíduos que dela fazem parte. Dessa maneira, a relação se torna instituída, ou seja, pré-fabricada pelas instituições, definindo comportamentos fixos baseados em papéis e não na adaptação à realidade. Uma relação transversalizada é instituída porque se torna controlada de fora para dentro. A alta transversalidade em uma relação leva à cristalização dos papéis, o que permite que se viva sem reflexão, sem que haja qualquer responsabilidade pelos próprios atos.

Por conta do perigo de estagnação neurótica que a transversalidade em demasia pode apresentar, Lourau (1997) considera que as relações não devem ser instituídas, mas sim instituintes, isto é, adaptadas às circunstâncias, decididas e controladas pelas pessoas que dela fazem parte.

\section{Conclusão}

Os resultados do presente estudo permitiram rastrear as concepções sobre a formação da personalidade de autores fundamentais para a construção da psicossociologia como um campo fértil de pesquisa e intervenção. Contudo, sugere-se um aprofundamento da investigação da questão da personalidade na obra de outros autores relacionados ao movimento psicossociológico, tais como Lapassade, para uma ampliação dos achados deste estudo. 
CASE, K. A., FISHBEIN, H. D., \& RITCHEY, P. N. Personality'sinfluence on higher order factors of prejudice and discrimination. Current Research in Social Psychology, 11, p. 187-201, 2006.

BLACKBURN, S. Dicionário Oxford de Filosofia. Rio de Janeiro: Zahar, 1997.

ENRIQUEZ, E. O papel do sujeito na dinâmica social. Em: M.M. Machado; E.M. Castro (Orgs). Psicossociologia: análise social e intervenção. Petrópolis: Vozes, 2001.

KRÜGER, H. Introdução à psicologia social. São Paulo: E.P.U., 1986.

LANE, S.T.M.; CODO, W. Psicologia social: o homem em movimento. São Paulo: Brasiliense, 2001.

LAPASSADE, G. Grupos, organizações e instituições. Rio de Janeiro: Francisco Alves, 1977.

LOURAU, R.. A Análise Institucional. Petrópolis: Vozes, 1997.

MACHADO, M.N.M. Intervenção psicossociológica: método clínico, de pesquisa e de construção teórica. Pesquisas e práticas psicossociais, 5(2), p.110-123, 2010.

MYERS, D.G. Psicologia Social. São Paulo: LTC, 1997.

SARTRE J.P. O existencialismo é um humanismo. São Paulo: Abril Cultural, 1973.

SARTRE J.P. Crítica da razão dialética. São Paulo: DP\&A, 1960/2002.

TROTTER, W. Instincts of the herd in peace and war. Oxford: University Press, 1953. 